\title{
PENGARUH EKSTRAK BUAH Carica pubescens Lenne \& K. Koch YANG TUMBUH DI BEBERAPA TEMPAT DI INDONESIA TERHADAP PENYEMBUHAN LUKA MUKOSA RONGGA MULUT
}

\author{
Risma Aprinda Kristanti \\ Jurusan Biologi Fakultas Sains dan Teknologi \\ Universitas Islam Negeri Maulana Malik Ibrahim Malang \\ E-mail: risma.aprinda@yahoo.com
}

\begin{abstract}
The aim of this study is to examine the effect of Carica pubescens Lenne \& K. Koch extract to the epihtelialization on the wound healing of gingival mucosa and to examine the effect of $C$. pubescens extract from different region (Dieng and Cangar) to the epithelialization process.Twenty eight adult male albino rats were devided into four group, we created cutlet along $1 \mathrm{~cm}$ on the mandibular gingival mucosa below insisiv teeth. K1 group were treated with aquadest while K2 group were treated with $C$. pubescens extract from Dieng, K3 group were treated with $C$. pubescens extract from Cangar, and K4 group were treated with policresulen preparations. At the end of fifth day, the rats were sacrificed and the mandibular gingival mucosa were collected for histologist preparations. The result of this study shows that K3 group has the thickest gingival epithel layers while there is no significant different among four group for the thikness gingival epithel layers.

Key word: epithel, epithelialization, gingival, wound, mucosa, oral, C. pubescens
\end{abstract}

\section{PENDAHULUAN}

Perlukaan pada mukosa mulut sering dijumpai dalam praktek kedokteran gigi. Luka pada mukosa mulut dapat disebabkan oleh berbagai agen fisik maupun kimiawi, seperti trauma, suhu panas atau dingin, sayatan benda tajam, dan paparan zat kimia (Underwood, 1999). Obat yang saat ini banyak digunakan di masyarakat umtuk pengobatan luka mukosa rongga mulut adalah sediaan policresulen yang umum ada di pasaran. Policresulen mempunyai efek selektif hanya bekerja terhadap jaringan rusak atau patologis, yaitu koagulasi dan kemudian dikeluarkan atau dilepaskan. Sedangkan epitel skuamosa yang sehat tidak dipengaruhi oleh obat ini. (Lacy \& Amstrong 2009). Obat-obatan yang ada di pasaran sebagian besar dapat menyebabkan efek samping yang tidak diharapkan, oleh karena itu obat herbal dapat menjadi alternatif pengobatan (Manson \& Eley, 1993; Lewis \& Lamey, 1998).

Dewasa ini studi mengenai tanaman obat dan potensinya banyak dikembangkan, tidak terkecuali untuk kesehatan gigi dan rongga mulut. C. pubescens merupakan salah satu tanaman khas dataran tinggi di Indonesia dengan kandungan vitamin $\mathrm{C}$ tinggi yang berpotensi sebagai bahan alami dalam penyembuhan mukosa mulut. Selain itu, buah $C$. pubescens juga mengandung Vitamin A. Vitamin A yang yang berupa asam retinoat memiliki peranan dalam differensiasi sel, sehingga vitamin A mengatur pada proses reepitelisasi pada mitosis sel-sel di sekitar luka (MacKay \& Miller, 2003).

Di Indonesia, $C$. pubescens dapat dijumpai di Dataran Tinggi Dieng, Jawa Tengah; di Cangar, Batu; dan Bromo Tengger, Jawa Timur. C. pubescens merupakan spesies yang beradaptasi di tempat dengan ketinggian 1.400-2.400 meter di atas permukaan laut (dpl), temperatur rendah, dan curah hujan tinggi.

Ketinggian yang berbeda bisa menentukan faktor lingkungan iklim serta proses metabolisme tanaman. Cuaca adalah keadaan atau kelakuan atmosfer pada waktu tertentu yang sifatnya berubah-ubah dari waktu ke waktu, sedangkan iklim adalah rata-rata keadaan cuaca dalam jangka waktu yang cukup lama, minimal 30 tahun yang sifatnya tetap (Kartosapoetra, 2004).

Pengaruh iklim terhadap tanaman diawali oleh pengaruh langsung cuaca terutama radiasi dan suhu terhadap fotosintesis dan proses metabolisme lain di dalam sel organ tanaman. Fotosintesis dan respirasi merupakan awal proses hidup. Kedua proses tersebut berlangsung serentak, hanya saja fotosintesis berlangsung pada periode cahaya matahari siang hari atau perlakuan dengan lampu, sedang respirasi 
berlangsung terus-menerus (Fitriningrum dkk, 2013).

\section{MATERI DAN METODE PENELITIAN}

Jenis penelitian ini adalah penelitian eksperimental laboratoris dengan rancangan penelitian the post test only control group design. Penelitian dilakukan di Laboratorium Fisiologi Hewan dan Laboratorium Optik UIN Maliki Malang, serta Laboratorium Histologi Universitas Brawijaya Malang.

\section{Sampel}

Sampel yang digunakan dalam penelitian ini adalah tikus putih Rattus norvegicus sebanyak 28 buah, berusia 40- 60 hari dengan berat 150 -200 gram, dalam keadaan sehat dan belum pernah digunakan untuk penelitian.

Sampel dibagi menjadi 4 kelompok, yaitu K1, K2, K3, dan K4. Kelompok K1 adalah kelompok control, pada kelompok ini hewan coba hanya dibuat luka pada mukosa gingiva dan diberikan larutan aquadest secara topical pada daerah luka. Pada kelompok K2 hewan coba dibuat luka pada mukosa gingiva dan diberikan larutan ekstrak buah $C$. pubescens yang berasal dari daerah Dieng secara topikal pada daerah luka. Pada kelompok K3 hewan coba dibuat luka pada mukosa gingiva dan diberikan larutan ekstrak buah C. pubescens yang berasal dari Cangar secara topical pada daerah luka. Pada K4 hewan coba dibuat luka pada mukosa gingiva dan diberikan sediaan policresulen yang umum ada di pasaran secara topical pada daerah luka.

\section{Induksi Luka Mukosa Rongga Mulut}

Induksi luka mukosa rongga mulut dilakukan dengan membuat sayatan menggunakan mess no.3 pada mukosa labial tikus, di bawah gigi insisiv rahang bawah. Sayatan dibuat sepanjang $1 \mathrm{~cm}$ dengan kedalaman sampai mencapai tulang alveolar. Setelah dibuat sayatan, untuk mempercepat pembentukan luka, diaplikasikan larutan peroksida $\left(\mathrm{H}_{2} \mathrm{O}_{2}\right) \quad 30 \%$ menggunakan cotton pellet pada daerah luka selama 3 detik.

\section{Pemberian Ekstrak Buah C. pubescens}

Pada penelitian ini digunakan ekstrak buah C. pubescens dengan konsentrasi $100 \%$.
Pembuatan ekstrah buah $C$. pubescens dilakukan dengan menggunakan metode maserasi menggunakan etanol. Pemberian ekstrak buah $C$. pubescens dilakukan sehari setelah pembuatan luka sampai dengan hari ke-5 dengan menggunakan mikropipet pada daerah mukosa gingiva yang telah dilukai. Ekstrak buah $C$. pubescens diberikan pada kelompok K2 dan K3 sebanyak $100 \mu \mathrm{l}$ untuk setiap tikus. Pada kelompok K2 diberikan ekstrak buah $C$. pubescens yang berasal dari Daerah Dieng, sedangkan pada K3 diberikan ekstrak buah $C$. pubescens yang berasal dari Cangar.

\section{Pengambilan Data}

Pada hari ke-6, semua tikus dikorbankan dan diambil mukosa gingiva labial rahang bawah untuk dibuat sediaan histologis. Setelah sediaan histologis selesai dibuat, dilakukan pengukuran ketebalan epitel gingiva menggunakan micrometer grid. Data yang didapat diuji normalitas dengan KolmogorovSmirnov. Untuk melihat perbedaan ketebalan epitel antar kelompok dilakukan Uji GamesHowell.

\section{HASIL PENELITIAN}

Berdasarkan penelitian yang telah dilakukan, diperoleh hasil rata-rata ketebalan epitel gingiva tikus pada masing-masing kelompok sebagai berikut:

Tabel 1. Nilai rerata (mean) dan simpang baku (SD) ketebalan epitel gingiva tikus pada kelompok K1, K2, K3, dan K4

\begin{tabular}{ccc} 
Kelompok & $\mathbf{N}$ & Mean dan SD \\
\hline K1 & 7 & $3,484 \pm 0,941$ \\
K2 & 7 & $2,712 \pm 0,654$ \\
K3 & 7 & $5,244 \pm 3,103$ \\
K4 & 7 & $3,479 \pm 1,295$ \\
\hline \multirow{2}{*}{ Total } & 28 & $3,730 \pm 1,923$ \\
\end{tabular}




\section{Risma Aprinda Kristanti}
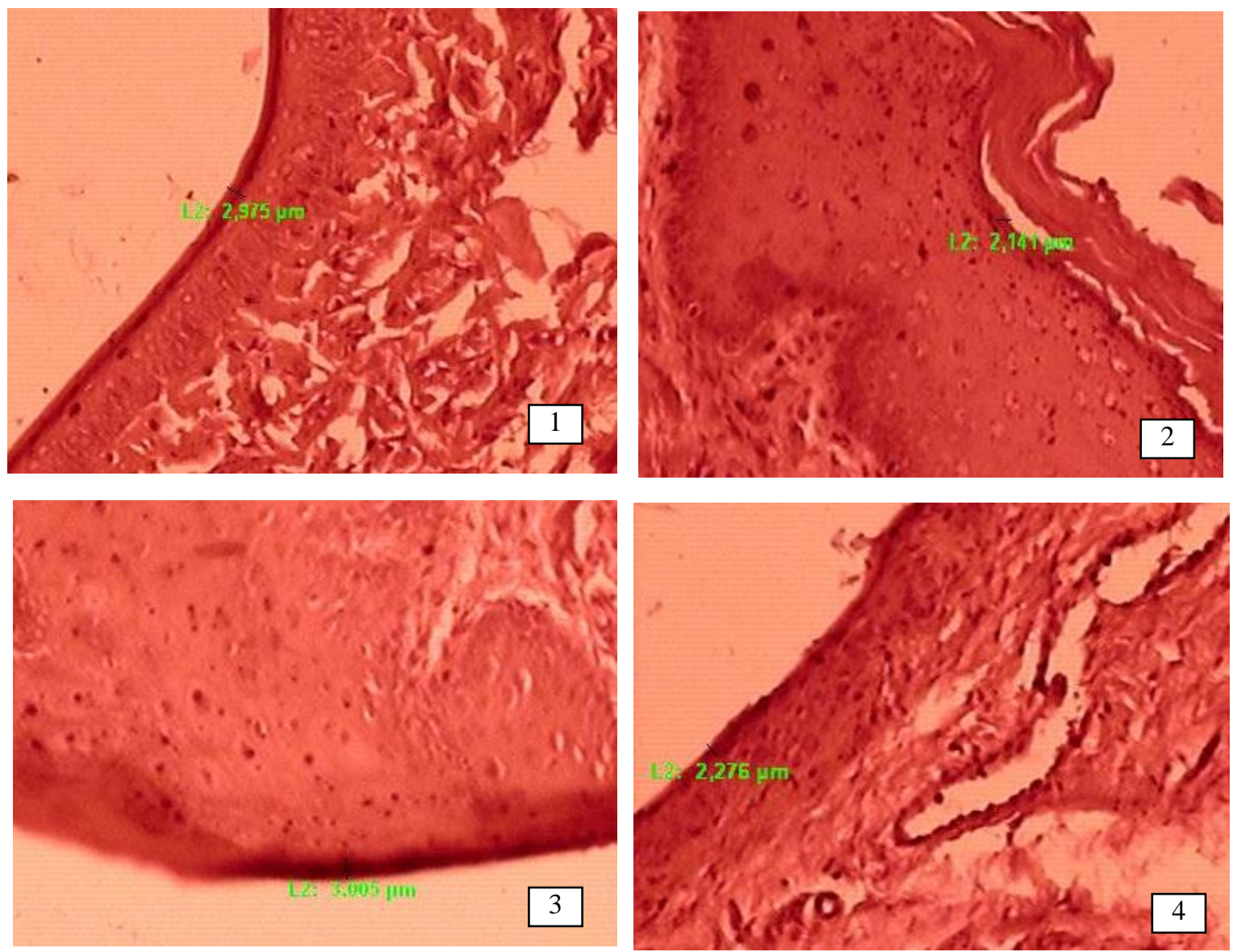

Gambar 1. Gambaran histologis epitel gingiva kelompok K1 (1); Gambaran histologis epitel gingiva kelompok K2 (2); Gambaran histologis epitel gingiva kelompok K3 (3); Gambaran histologis epitel gingiva kelompok K4 (4)

Data terlebih dahulu diuji normalitas Kolmogorov-smirnov dan menunjukkan $(p>0,05)$ sehingga dapat disimpulkan bahwa data berdistribusi normal, selanjutnya dilakukan uji homogenitas menggunakan uji Levene test, setelah diuji menunjukkan $(\mathrm{p}<0,05)$ artinya data tidak homogen, selanjutnya untuk mengetahui beda variabel tebal epitel gingiva antar kelompok dilakukan Brown-Forsythe Test. Hasil selengkapnya dapat dilihat pada tabel berikut:

Tabel 2. Hasil uji beda Games-Howell ketebalan epitel gingiva pada kelompok K1, K2, K3 dan K4

\section{Kelompok \\ p \\ Keterangan}

\begin{tabular}{lll} 
K1 dan K2 & 0,333 & Tidak signifikan \\
K1 dan K3 & 0,518 & Tidak signifikan \\
K1 dan K4 & 1,000 & Tidak signifikan \\
K2 dan K3 & 0,243 & Tidak signifikan \\
\hline
\end{tabular}

\begin{tabular}{lll}
\hline K2 dan K4 & 0,531 & Tidak signifikan \\
K3 dan K4 & 0,539 & Tidak signifikan
\end{tabular}

Tabel 2 menunjukkan bahwa tidak terdapat perbedaan yang signifikan untuk ketebalan epitel gingiva antar kelompok.

\section{PEMBAHASAN}

C. pubescens merupakan salah satu tanaman khas dataran tinggi di Indonesia dengan kandungan Vitamin $\mathrm{C}$ tinggi yang berpotensi sebagai bahan alami dalam penyembuhan mukosa mulut. Di Indonesia, C. pubescens dapat dijumpai di Dataran Tinggi Dieng, Jawa Tengah dan di Cangar, Batu, dan Bromo Tengger, Jawa Timur. C. pubescens merupakan spesies yang beradaptasi di tempat dengan ketinggian $1.400-$ 2.400 meter di atas permukaan laut (dpl), temperatur rendah, dan curah hujan tinggi.

Beberapa komponen dalam tanaman $C$. pubescens terbukti memiliki aktivitas yang 
signifikan dalam penyembuhan penyakit, diantaranya adalah minyak atsiri, polifenol, dan flavanoid. Minyak atsiri berfungsi sebagai antibakteri sehingga dapat mempercepat netralisasi bahan asing (Parwata dan Dewi, 2008). Polifenol berfungsi sebagai antihistamin. Sedangkan manfaat flavonoid antara lain adalah untuk melindungi struktur sel, memiliki hubungan sinergis dengan vitamin $\mathrm{C}$ (meningkatkan efektivitas vitamin C), mencegah keropos tulang, antibiotik, dan sebagai antiinflamasi. Selain memiliki kandungan vitamin $\mathrm{C}$ yang tinggi, C.pubescens juga mengandung vitamin A (Ahkam, 2008; Hidayat, 2001). Adanya senyawa-senyawa tersebut dapat memungkinkan C.pubescens dapat digunakan sebagai obat herbal yang dapat meningkatkan kecepatan regenerasi epitel pada penyembuhan luka. Penelitian ini bertujuan mengkaji lebih dalam tentang pengaruh pemberian ekstrak C.pubescens yang berasal dari daerah Dieng dan Cangar terhadap kecepatan regenerasi epitel pada penyembuhan luka mukosa rongga mulut pada tikus putih jantan Galur Wistar (Rattus norvegicus).

Penelitian ini merupakan penelitian eksperimental laboratories yang memenuhi kriteria sebagai penelitian eksperimen murni (true experiment). Perlakuan terhadap sampel penelitian dilakukan pada ruangan yang telah tersedia dan pemeriksaan terhadap variabel yang diukur dilakukan di laboratorium (Zainuddin, 2000).

Rancangan penelitian yang digunakan adalah post test only control group design karena hewan coba dibagi menjadi 4 kelompok menggunakan teknik alokasi random dan data variabel tergantung untuk masing-masing sampel diperoleh hanya setelah perlakuan atau tidak dilakukan pengambilan data variabel tergantung sebelum perlakuan (Zainuddin, 2000).

Hasil analisa deskriptif menunjukkan bahwa rerata ketebalan epitel gingiva untuk kelompok kontrol adalah 3,484 $\mu \mathrm{m}$, untuk kelompok yang diberi ekstrak C.pubescens dari daerah Dieng adalah 2,712 $\mu \mathrm{m}$, untuk kelompok yang diberi ekstrak C.pubescens dari daerah Cangar adalah 5,244 $\mu \mathrm{m}$, dan untuk kelompok yang diberi sediaan policresulen adalah 3,479 $\mu \mathrm{m}$. Hal ini menunjukkan bahwa epitel gingiva memiliki ketebalan paling tebal pada kelompok yang mendapatkan pemberian ekstrak buah C.pubescens yang berasal dari daerah Cangar, sedangkan epitel gingiva yang memiliki ketebalan paling tipis adalah pada kelompok yang mendapatkan pemberian ekstrak buah C.pubescens yang berasal dari daerah Dieng.

Hasil yang diperoleh tersebut dapat disebabkan karena buah $C$. pubescens sebagai bahan utama ekstrak memiliki tingkat kematangan yang berbeda antara yang berasal dari daerah Dieng dan daerah Cangar. Menurut Abidin (1991) selama proses pematangan buah terjadi perubahan dalam berbagai segi antara lain perubahan struktur, tekstur, warna, rasa, dan proses biokimia yang terjadi di dalamnya. Hal ini tentu juga mempengaruhi kandungan senyawa yang terdapat dalam buah $C$. pubescens.

Selain itu, pada proses metabolisme tanaman, suhu juga mempengaruhi kecepatan respirasi yang cenderung menurun pada suhu rendah, sehingga hasil fotosintesis kalau tidak direspirasi diubah menjadi bentuk lain, dan untuk adaptasi terhadap tekanan lingkungan yang ekstrim tumbuhan mengembangkan antioksidan termasuk Vitamin $\mathrm{C}$ dan keasaman tinggi. Di dalam metabolisme karbohidrat dijelaskan bahwa Vitamin $\mathrm{C}$ memang dibuat dari monosakarida melalui serangkaian proses biokimia yang melibatkan enzim-enzim yang akan mengubah molekul D-Glukosa-6-P akhirnya menjadi vitaminC (L-Ascorbic acid) (Wheeler et al., 1998). Telah diketahui bahwa Vitamin C merupakan salah satu kandungan utama dari buah $C$. pubescens yang memiliki kemampuan mempercepat proses epitelisasi. Vitamin $\mathrm{C}$ berperan dalam sintesis kolagen, proteoglikan dan komponen organik lain dalam intrasellular matrik jaringan seperti tulang, kulit, dinding kapiler, dan jaringan ikat yang lain (MacKay \& Miller, 2003). Hal ini juga dibuktikan oleh penelitian sebelumnya bahwa bahwa terjadi peningkatan ketebalan epital gingival pada tikus wistar jantan (Astuti, 2005). Vitamin $\mathrm{C}$ akan mengaktifkan katalisator ion $\mathrm{Fe}^{2+}$ dan ion $\mathrm{Cu}^{+}$yang akan mengaktifkan enzim-enzim pada proses hidroksilasi asam amino prolin dan lisin menjadi hidroksiprolin dan hidroksilisin. Reaksi hidroksilasi ini diperlukan untuk mengadakan perlekatan silang (cross linking) dan tripel helix pada jaringan sehingga didapat struktur jaringan yang sehat dan kuat (Yendriwati, 2006). Jika proses proliferasi yang meliputi sintesis kolagen dapat tercapai, maka proses epitelisasi akan berlangsung lebih cepat.

Dari hasi Uji Games-Howell diketahui bahwa tidak terdapat perbedaan yang signifikan 
untuk ketebalan gingiva antara keempat kelompok. Hal ini dapat disebabkan karena dalam penelitian ini belum menggunakan konsentrasi dan dosis yang optimal untuk pemberian ekstrak buah $C$. pubescens dan sediaan policresulen untuk diberikan kepada hewan coba sehingga hasil yang didapat tidak jauh berbeda dengan kelompok kontrol.

\section{KESIMPULAN DAN SARAN}

Berdasarkan penelitian yang telah dilakukan dapat disimpulkan bahwa pemberian ekstrak buah C. Pubescens yang berasal dari Daerah Dieng tidak dapat mempercepat proses epitelisasi pada proses penyembuhan luka mukosa rongga mulut pada tikus Rattus norvegicus. Sedangkan pemberian ekstrak buah C. Pubescens yang berasal dari Daerah Cangar dapat mempercepat proses epitelisasi pada proses penyembuhan luka mukosa rongga mulut pada tikus Rattus norvegicus.

Saran yang dapat diberikan adalah perlu penelitian lebih lanjut tentang pengaruh ketinggian dan keadaan iklim daerah terhadap kandungan senyawa aktif buah $C$. pubescens yang bermanfaat terhadap proses`epitelisasi pada penyembuhan luka mukosa rongga mulut. Selain itu, juga perlu dilakukan penelitian lebih lanjut tentang dosis optimal ekstrak buah $C$. pubescens yang dapat digunakan untuk membantu mempercepat proses`epitelisasi pada penyembuhan luka mukosa rongga mulut.

\section{DAFTAR PUSTAKA}

Abidin Z. 1991. Dasar-dasar Pengetahuan Ilmu Tanaman. Angkasa,Bandung

Ahkam, MS. 2008. Obat Alternatif: Sarang Semut Penakluk Penyakit Maut. www.sarangsemut.50webs.com

Astuti, DI. 2005. Gambaran Mikroskopois Ketebalan Epitel Gingiva Setelah Pemberian Vitamin C Pada Proses Penyembuhan Luka Pada Tikus Wistar Jantan. Tidak diterbitkan. Skripsi. Jember: Fakultas Kedokteran Gigi Universita Jember

Fitriningrum R, Sugiyarto and Susilowati A. 2013. Analisis Kandungan Karbohidrat Pada Berbagai Tingkat Kematangan Buah Karika (Carica pubescens) Di Kejajar Dan Sembungan, Dataran Tinggi Dieng, Jawa Tengah. Bioteknologi 10 (1): 6-14. ISSN: 02166887, EISSN: 2301-8658
Kartosapoetra AG. 2004. Klimatologi; Pengaruh Iklim terhadap Tanah dan Tanaman. Bumi Aksara, Jakarta

Lacy, C.F., Amstrong, L.L, 2008. Drug Information Handbook, Ed. 17th.USA : Lexi-Comp Inc.

Lewis, M. A. O dan P. J Lamey. 1998. Tinjauan Klinis Penyakit Mulut. Terjemahan Elly Wiriawan. Jakarta: Widya Medika

MacKay, Douglas and alan L. Miller, Nutrional Support for Wound Healing. Alternative Reviews. Vol 8 No.4 (2003).

Manson, J.D dan B. M. Eley. 1993. Buku Ajar Periodonti Edisi 2. Terjemahan oleh Anastasia S dari Outline of Periodontics. Jakarta: Hipokrates

Parwata, Adi IMO, Dewi, Sastra PF. 2008. Isolasi dan Uji Aktivitas Antibakteri Minyak Atsiri Dari Rimpang Lengkuas. ejournal.unud.ac.id

Underwood, JCE. 1999. Patologi Umum dan Sistematik. Jakarta: EGC

Wheeler GL, Jones MA, Smirnoff N. 1998 The Biosynthetic Pathway Of Vitamin C In Higher Plants. Nature. 393 (6683): 365369

Yendriwati, Kebutuhan Vitamin $C$ dan Pengaruhnya terhadap Kesehatan Tubuh dan Rongga Mulut. Dentika Dental Journal, Vol 11, No. 1 : (2006) 78-83.

Zainuddin, M. 2000. Metodologi Penelitian. Surabaya: Pasca Sarjana Unair 